\title{
Correction and clarification
}

\author{
(C) $(\Theta \Theta$ OPEN ACCESS
}

\section{Endorsing performance measures is a matter of trust}

This article by Peter Eichacker and colleagues (doi:10.1136/ bmj.k703, 23 Feb 2018) incorrectly states that the primary developer of SEP-1 continued to receive financial support from Edwards Lifesciences. Edwards Lifesciences has since told The $B M J$ that the primary developer of SEP-1 has not received payments from Edwards Lifesciences since 2009, nor any other reportable transfers of value (eg, meals, travel) since before August 2013.

Although the article correctly states that there are compelling incentives for hospitals to follow the SEP-1 measure, we would like to clarify that the measure is not mandatory and is not part of a value based purchasing programme. 